\title{
El apoyo diplomático de Panamá a la Argentina en torno a la Cuestión Malvinas durante el período torrijista (1969-1983). Un análisis desde el prisma de la autonomía
}

Panama's diplomatic support to Argentina concerning the Malvinas sovereignty dispute during the Torrijos era (1969-1983). An analysis from the autonomy viewpoint

Bruno Rossi Pizzi ${ }^{12}$

\section{Resumen}

El objeto del presente artículo es escudriñar la postura de la República de Panamá en torno a la Cuestión Malvinas durante el período del torrijismo (19691983), a partir del prisma de la teoría de la autonomía. Luego de haber descrito en líneas generales la política exterior del régimen gobernante, analizamos, en primer lugar, la firma de la declaración Perón-Torrijos de enero de 1974-los intereses que la suscitaron, sus fundamentos y su sostenimiento en el tiempo. Seguidamente, hacemos especial hincapié en el accionar de la diplomacia panameña ante el conflicto armado de 1982, máxime teniendo en cuenta que, en aquel año, Panamá era el único país latinoamericano en ocupar un asiento en el Consejo de Seguridad de las Naciones Unidas. A modo de conclusión, sostenemos que el apoyo panameño a la Argentina en torno a la Cuestión Malvinas ha sido una manifestación de su vocación autonomista en el período estudiado.

Palabras clave: Malvinas, Panamá, Argentina, Torrijismo, Autonomía

\footnotetext{
Recibido: 9 de febrero de 2020 Aceptado: 20 de abril de $2021 \sim$ Publicado: 8 de julio de 2021

${ }^{1}$ Licenciado en Relaciones Internacionales. Universidad Nacional de Rosario (UNR), Rosario, Argentina. Miembro del Grupo de Estudios sobre Malvinas de la Facultad de Ciencia Política y Relaciones Internacionales de la Universidad Nacional de Rosario. Correo electrónico: bruropi96@hotmail.com ID https://orcid.org/0000-0002-6936-5281

2 Este trabajo fue presentado como ponencia en el Simposio "La Cuestión Malvinas a 55 años de la Resolución 2065”-organizado por la Secretaría de Malvinas, Antártida y Atlántico Sur del Ministerio de Relaciones Exteriores, Comercio Internacional y Culto de la República Argentina y por el Consejo Latinoamericano de Ciencias Sociales (CLACSO) - llevado a cabo durante los días 16 y 17 de diciembre de 2020. El autor desea expresar su profundo agradecimiento a Dalys Vargas, Luz Divina Arredondo y Carla María Morasso.
} 


\section{Abstract}

The aim of this article is to scrutinize the position of the Republic of Panama regarding the Malvinas sovereignty dispute during the Torrijos era (1969-1983) from the autonomy framework. After briefly describing the regime's foreign policy, we analyze the signing of the 1974 Perón-Torrijos declaration-the interests that aroused it, and the rationale behind it. We emphasize, thereupon, the actions of Panamanian diplomacy vis-à-vis the 1982 armed conflict, especially considering that Panama was the only Latin American country to occupy a seat on the UN Security Council at the time. As a conclusion, we assert that Panama's diplomatic support to Argentina concerning the Malvinas sovereignty dispute has been a manifestation of its autonomist vocation during the studied period.

Keywords: Malvinas, Panama, Argentina, Torrijos, Autonomy

\section{Introducción}

"Panamá apoya a la Argentina en su justa aspiración para que se devuelva a su soberanía el territorio de las Malvinas." Memoria de la Cancillería panameña, 1978/1979.

La historiografía de las relaciones internacionales ha abordado, en numerosas oportunidades, la Guerra de las Malvinas -y la Cuestión Malvinas en sí- desde un enfoque multilateral enraizado en Latinoamérica ${ }^{3}$. Así, los análisis suelen hacer hincapié en el activo apoyo peruano a la República Argentina, o en el viaje del Canciller argentino Costa Méndez a Cuba. No obstante, poco se ha conceptualizado en torno al rol de Panamá en el conflicto. Nos proponemos hacer un examen de la postura de la República de Panamá sobre la Cuestión Malvinas durante el régimen torrijista, partiendo de la teoría de la autonomía como marco teórico-conceptual.

En función del objetivo planteado, creemos conveniente estructurar el presente artículo de la siguiente manera. Además de esta introducción y los comentarios finales a modo de conclusión, hemos incluido tres secciones. La primera de ellas tiene por objeto describir brevemente la política exterior de Panamá durante el torrijismo, a los efectos de contextualizar el apoyo de ese país a la República Argentina en torno a la Cuestión Malvinas. Asimismo, en dicho apartado se explicita

\footnotetext{
${ }^{3}$ Véanse, por ejemplo, los enriquecedores debates y ponencias que tuvieron lugar en el marco del Primer Congreso Latinoamericano "Malvinas, una Causa de la Patria Grande", celebrado en la Universidad Nacional de Lanús, Argentina, en 2010 (Cardozo, 2013).
} 
el marco teórico a partir del cual realizamos el análisis i.e.: la escuela de la autonomíapuntualmente los escritos del Dr. Juan Carlos Puig. Seguidamente, le dedicamos una sección al abordaje de la Declaración Perón-Torrijos de 1974, para luego explicar su sostenimiento en el tiempo. La última sección está consagrada al estudio de la diplomacia panameña durante la Guerra de Malvinas de 1982, haciendo énfasis en el accionar de Panamá en el Consejo de Seguridad de las Naciones Unidas desde abril hasta junio de 1982.

\section{1- La política exterior de Panamá durante el torrijismo. Consideraciones generales desde el lente autonomista}

"El panameño no sale con un paraguas cuando está lloviendo en Moscú. Eso es mentira. El panameño no se pone un sobretodo cuando está cayendo nieve en Washington. Eso es mentira. El panameño está buscando su propia solución.” Gral. Omar Torrijos Herrera.

En primer lugar, hemos de señalar determinadas características del torrijismo y su política exterior ${ }^{4}$. Llamamos torrijismo a un momento en particular durante el largo período del régimen militar de Panamá (1968-1989) ${ }^{5}$. La etapa a la que nos referimos es aquella forjada en torno a la conducción y las ideas del General Omar Torrijos Herrera, quien irrumpe y se consolida como líder panameño en 1969. Si bien Torrijos falleció en 1981, ha existido una continuidad en las ideas y doctrinas de política exterior panameña hasta 1983, año en el que un referéndum constitucional habría de "poner fin de hecho a la era Torrijos" (Ceberio, 23 de abril de 1983).

Es menester destacar que ha sido durante el período torrijista que Panamá ha reafirmado su soberanía sobre el homónimo Canal y su Zona, por medio de la firma de los denominados Tratados Torrijos-Carter en 1977. Tal ha sido el logro por antonomasia de la política exterior panameña en aquellos años: el abordaje de la espinosa Cuestión Canalera; tanto más cuanto que fue durante esta etapa que este contencioso, tan significativo para las relaciones entre Estados Unidos y la región latinoamericana, hubo de hallar su resolución por la vía diplomática y de la

\footnotetext{
${ }^{4}$ Este artículo deriva de un trabajo de investigación más amplio que redundó en la tesina de grado del autor. La misma se denomina "La política exterior panameña en el período torrijista (1969-1983). Un análisis desde el prisma de la autonomía”.

${ }^{5} \mathrm{Al}$ respecto de la extensa duración del régimen militar panameño en su conjunto y de cómo éste ha logrado mantenerse durante más de dos décadas, véase Ropp (1992).
} 
negociación entre las naciones. En este punto, es evidente que, a la sazón, el Canal de Panamá y la Cuestión Malvinas eran los enclaves coloniales con mayor carga simbólica en la región Latinoamericana ${ }^{6}$.

En términos doctrinarios, la política exterior de Panamá en el período torrijista, como lo atestiguan las Memorias anuales del Ministerio de Relaciones Exteriores del país centroamericano, se caracterizó por ser tanto dinámica (al poner en tensión los recursos estatales en pos de la causa de la soberanía efectiva sobre todo el territorio), cuanto independiente (al poner por delante el interés nacional allende los dictados de las fuerzas foráneas), nacionalista (al plantearse como objetivo primordial la soberanía sobre el Canal y su Zona) y No Alineada (al propugnar un desarrollo nacional independiente de la confrontación Este-Oeste) ( $c f r$. Ministerio de Relaciones Exteriores de la República de Panamá, 1976, p. 5-6). Es por ello que consideramos que la política exterior torrijista puede ser analizada desde el prisma de la autonomía.

La Escuela de la autonomía, fundamentalmente la corriente encabezada por el académico argentino Juan Carlos Puig, se trata de un enfoque desarrollado en las décadas de 1970 y 1980 desde y con miras a la región latinoamericana. En este sentido, bien podemos inscribirla en el contexto del "pensamiento latinoamericano", ya que sin desconocer los valiosos aportes del mainstream de la disciplina de las Relaciones Internacionales- propone un abordaje localizado, atendiendo a la pertenencia de América Latina al denominado Sur Global ${ }^{7}$.

La lectura puigiana del escenario global de la época se forja en la existencia, a juicio del autor, de una progresiva permisividad para los actores tercermundistas en el seno de los regímenes internacionales imperantes. Dicha visión colisiona con las atávicas posturas de los tratadistas clásicos de la disciplina-i.e.: Hans Morgenthau o Raymond Aron- enraizadas en la concepción atomista de la comunidad internacional, la concepción del poder basado en la fuerza material y el predominio incontrastable de las grandes potencias (cfr. Puig, 1984, p. 29).

Frente a tal "espejismo internacional", Puig propone una caracterización menos conservadora del régimen internacional, merced a las tendencias contemporáneas a la sazón (décadas de 1970 y 1980) operantes. Efectivamente, el

\footnotetext{
${ }^{6} \mathrm{Si}$ bien excede a los objetivos del presente artículo, es interesante observar las estrategias esgrimidas por la diplomacia panameña para la consecución de su raison d'être, basadas en la internacionalización y multilateralización del conflicto, haciendo de la Cuestión Canalera una causa de la región Latinoamericana y del Tercer Mundo. Al respecto, véase Jaén Suárez (2007) y Tack (1981).

${ }^{7}$ A decir de Morasso (2015, p. 17), "La idea de Sur Global 'refiere a los países `periféricos 'en tanto unidades políticas que poseen menos recursos militares, políticos y económicos respecto a las unidades en el centro y por tanto son más vulnerables y carecen de condiciones para establecer las reglas del juego del sistema internacional."
} 
establecimiento de la OPEP, el proceso de descolonización y la derrota estadounidense en Vietnam, se interpretan, para el autor, como síntomas de modificaciones en los lineamientos del Sistema Internacional. Se trata de un mundo en donde los actores del Tercer Mundo tienden a un mayor margen de maniobra en la arena mundial ${ }^{8}$. Es en dicho contexto que se inserta la política exterior de Panamá durante el período torrijista.

Así, desde una perspectiva sistémica, Puig estudia los regímenes internacionales aseverando que puede detectarse un gradualismo en el continuum que va desde los conceptos antitéticos de "la autonomía pura (si bien teórica) hasta la dependencia pura (también teórica)” (Puig, 1971, p. 62). De esta suerte, construye una tipología de las situaciones dependientes, yendo del menor al mayor grado de autonomía posible de un Estado.

En primer lugar, esgrime la categoría de dependencia para-colonial, caracterizada por la posesión formal de "un gobierno soberano, pero en realidad éste, y aun los grupos que detentan el poder efectivo en la sociedad nacional no constituyen otra cosa que un apéndice del aparato gubernativo y de la estructura del poder real de otro Estado" (Puig, 1971, p. 63). Ascendiendo en la escala de autonomía, Puig presenta el concepto de dependencia nacional. La misma se da cuando los grupos que detentan el poder real "racionalizan la dependencia", puesto que consienten tamaña situación, tratando de sacar provecho de la misma; a veces en aras de una mayor autonomía futura (cfr. Puig, 1971, p. 64).

Luego de haber descrito la dependencia para-colonial y la dependencia nacional, Puig introduce el concepto de autonomía- subdividiéndolo en autonomía heterodoxa y autonomía secesionista. Esta última implica una confrontación directa con el o los centros de poder hegemónicos. Puig advierte acerca de los peligros del secesionismo, "si el país secesionista no tiene suficiente viabilidad o no se maneja con habilidad singular caerá inevitablemente en una nueva dependencia” (Puig, 1971, p. $66)$.

Empero, es en el concepto de autonomía heterodoxa donde yace el leitmotiv del marco teórico puigiano.

En este estadio, los supremos repartidores nacionales del Estado que forman parte integrante de un bloque siguen aceptando la conducción estratégica de la potencia dominante, pero discrepan abiertamente con ella por lo menos en tres cuestiones importantes: a) en el modelo de desarrollo interno, que puede no coincidir con las expectativas de la

\footnotetext{
${ }^{8}$ Los esfuerzos para la creación del denominado Nuevo Orden Económico Internacional por parte de los actores del Sur Global hacia 1974 se ofrecen como ejemplos de la permisibilidad de los países medianos y pequeños, en concomitancia con la caracterización de Puig.
} 
metrópoli; b) en las vinculaciones internacionales que no sean globalmente estratégicas; c) en el deslinde entre el, interés nacional de la potencia dominante y el interés estratégico del bloque. (Puig, 1984, p. 78).

Consideramos, prima facie, atinada la categoría de autonomía heterodoxa para llevar a cabo un análisis de la política exterior panameña en el período torrijista, por cuanto Panamá, si bien hubo de confrontar con el hegemón (Estados Unidos) en diversas cuestiones de índole política, jamás ha renegado de la conducción estratégica del bloque.

Por otra parte, el autor asevera que embarcarse en el largo y sinuoso camino de dicha autonomización progresiva constituye una "política extremadamente riesgosa", en la que el Estado en cuestión "no puede contar con más que sus propias fuerzas y eventualmente, con las de los otros países del mismo bloque o no alineados solidarios con su causa" (Puig, 1984, p. 72). Este último punto es insoslayable para nuestro ejercicio de análisis de la política exterior panameña a través del prisma de la Escuela de la Autonomía; no solamente desde la arista en donde Panamá ha buscado solidaridad para con su causa propia, sino también desde la faceta cooperativa de la política exterior panameña, cuyo perfil se ha destacado por haber hecho propias causas autonomistas ajenas, como la Cuestión Malvinas.

Habiendo establecido las consideraciones precedentes, nos introduciremos ahora de forma acabada el abordaje de la Cuestión Malvinas por parte del régimen torrijista. Si bien se observa que el apoyo diplomático de la República de Panamá a la Argentina en lo atinente a la Cuestión Malvinas fue continuo y sostenido durante todo el período que va desde 1969 hasta 1983, en el presente artículo nos enfocaremos en las acciones de la diplomacia panameña durante la guerra del Atlántico Sur de 1982, dado que ha sido en el marco de tamaña conflagración que se tornó más ostensible la vocación autonomista del torrijismo y su abierta disputa con los hegemones en diversos foros regionales y globales. Empero, juzgamos atinado abrevar en algunos antecedentes de la posición panameña en torno a la disputa por Malvinas, como así también en los fundamentos de la misma.

\section{2- La declaración bilateral Perón-Torrijos de 1974 y su proyección en el tiempo}

"El verdadero día de las Américas llegará en toda su plenitud cuando, por ejemplo, por vía de negociación y con respeto por los derechos involucrados, el Canal de Panamá sea definitivamente panameño, cuando las Islas Malvinas se reincorporen al patrimonio argentino.” 
Emb. Alejandro Orfila; Secretario General de la OEA.

Es menester considerar la visita de Estado del General Torrijos a la República Argentina de enero de 1974, atendiendo a la invitación formulada por el presidente Teniente General Juan Domingo Perón en una carta enviada el año anterior ${ }^{9}$. En aquella oportunidad, los líderes suscribieron una Declaración Conjunta sobre apoyo y asistencia recíproca en diversas materias. Dicho documento, enraizado en "la convicción de que la solidaridad y cooperación de todos los Estados latinoamericanos es base fundamental del progreso y bienestar de sus pueblos" (Declaración conjunta Argentino-Panameña, 1974), hizo explícito el intercambio de apoyos mutuos sobre las cuestiones que afectaban el ejercicio de la plena soberanía efectiva de ambas naciones, i.e.: la denominada Zona del Canal ${ }^{10}$ y la Cuestión Malvinas- a la sazón los vestigios de colonialismo más significativos y con mayor carga simbólica del continente. En la Declaración Conjunta, los líderes argüían que todo asunto que afectase la integridad territorial de los Estados americanos constituía una materia de interés común y prioritario para América Latina.

Lejos de tratarse de un mero entendimiento circunstancial con el peronismo, las bases de la declaración bilateral permanecieron incólumes incluso luego del golpe de Estado argentino de 1976. Lo cierto es que, más allá de la sincera solidaridad del gobierno panameño, Torrijos precisaba del apoyo de todos los líderes de la región latinoamericana en el tramo final de las negociaciones por los nuevos Tratados del Canal. Prueba de ello es la presencia de diversos gobernantes de facto como el boliviano Banzer Suárez o el chileno Pinochet Ugarte en la ceremonia de firma de los acuerdos Torrijos-Carter en la sede de la OEA, en septiembre de 1977 ( $c f r$. Greene, 1985, p. 112-113).

Desde luego que entre los presentes también se encontraba el presidente argentino de facto Jorge Rafael Videla, quien manifestó su apoyo al acuerdo alcanzado por los Estados Unidos y Panamá. En aquella oportunidad, en una declaración ante la prensa argentina, el General Torrijos se pronunció nuevamente sobre la Cuestión Malvinas, reafirmando la histórica postura panameña, cristalizada en la declaración

\footnotetext{
9 A entender de Puig (1984, p. 41), el cúmulo de las experiencias peronistas ha constituido el proyecto autonomista heterodoxo latinoamericano por antonomasia. Asimismo, es evidente el influjo que la doctrina justicialista de Tercera Posición ha tenido sobre el pensamiento y praxis torrijistas. El propio Torrijos hubo de afirmar: "me siento optimista acerca de los resultados de los esfuerzos de los pueblos latinoamericanos, dirigidos a mejorar el horizonte de su porvenir, de modo que la libre determinación, la soberanía política y económica, no sea un espejismo. No hay alternativa. El año 2000, como decía Perón, nos encontrará unidos o dominados" (Vargas y Zárate, 2017, p. 158-159).

${ }^{10}$ El período 1972-1976 se destacó por la internacionalización y multilateralización de la Cuestión Canalera por parte de la diplomacia panameña.
} 
bilateral de 1974. Más aún, sostuvo que no manifestarse así sería negar la propia causa panameña, en referencia a la Cuestión Canalera. En efecto, para Panamá, ambas controversias (Canalera y Malvinas) constituían ejemplos de vestigios coloniales que debían ser eliminados por medio de la diplomacia y la negociación entre las naciones. Torrijos esperaba que del ejemplo de los nuevos tratados del Canal se desprendieran numerosos ejemplos tendientes a la erradicación de todos los enclaves coloniales del continente, afirmando esto último con la venia y el consentimiento de Videla (Archivo DiFilm, 19 de febrero de 2017).

Se observa con este ejemplo una nueva manifestación del carácter autonomista de la política exterior panameña, al posicionarse en favor de la descolonización y los esfuerzos de otro país latinoamericano y miembro del Movimiento de los Países No Alineados en aras del control efectivo sobre la totalidad de su territorio. Dicho posicionamiento se enraíza no sólo en el interés del triunfo de la propia causa, sino que abreva del concepto de Patria Internacional ${ }^{11}$ - utilizado por el propio Omar Torrijos-, conforme al cual el torrijismo procuró convertir a Panamá en un faro moral del arreglo de los diferendos tercermundistas a partir de la diplomacia y la negociación entre las naciones.

No obstante, tanto la Declaración Conjunta de 1974 como los dichos de Torrijos sobre las Islas Malvinas en 1977 cobraron plena relevancia recién en 1982, al momento de producirse la Guerra del Atlántico Sur. Puesto que Panamá era en aquel entonces el único miembro latinoamericano del Consejo de Seguridad de las Naciones Unidas ${ }^{12}$, tuvo la oportunidad de defender la postura argentina en el foro diplomático por excelencia. Veamos cómo se comportó la política exterior panameña durante el conflicto armado de 1982.

\section{3- El accionar de la diplomacia panameña durante la Guerra del Atlántico Sur de 1982}

"Y no se diga, por tanto, como se ha querido decir aquí en una ocasión anterior, que la Argentina está invadiendo las Islas

\footnotetext{
${ }^{11}$ Como afirma la académica panameña Dalys Vargas (2004, p. 207), "los trabajos de investigación científica [sobre la política exterior panameña] han tendido a concentrarse en los hechos relacionados con la firma de los Tratados del Canal y su puesta en vigencia. Pero pocas personas conocen, recuerdan o comprenden otros aspectos de la febril actividad del General Torrijos en "la Patria Internacional," vinculados también con el perfeccionamiento de la soberanía y la independencia de Panamá, pero de un alcance que traspuso el territorio de nuestro país y las fronteras tradicionales de nuestra política exterior, proyectándose al futuro al ocuparse también con la situación de otros pueblos del mundo".

12 El país cursaba su tercera participación bienal como miembro no permanente del Consejo de Seguridad durante el período torrijista (1972-73; 1976-77; 1981-82).
} 
Malvinas. No puede un Estado invadir su propio suelo. Las Islas Malvinas son suelo argentino, de manera que allí no se puede hablar de invasión, sino de una situación en la que la

Argentina está ejerciendo sus derechos soberanos." Canciller panameño Jorge Illueca ante el Consejo de Seguridad de la

ONU.

Si bien es de capital importancia el accionar panameño en el Consejo de Seguridad de las Naciones Unidas al momento del conflicto armado, nuestro análisis no se limitará a dicho foro. Por el contrario, haremos mención al comportamiento de la diplomacia panameña en la OEA, el rol del Canal de Panamá en la conflagración bélica y a la alocución del presidente Arístides Royo ante las sesiones de la Asamblea General de la ONU dedicadas al desarme.

Al momento de producirse la denominada "Operación Rosario", por medio de la cual la República Argentina recuperó por la fuerza el control de las Islas Malvinas el 2 de abril de 1982, la crisis diplomática no se hizo esperar en el Consejo de Seguridad de las Naciones Unidas. Tamaña era la importancia del conflicto para la paz y seguridad internacionales que el propio canciller panameño Jorge Enrique Illueca Sibauste representó personalmente a su país en el recinto del Consejo, a partir de la sesión del 3 de abril ${ }^{13}$.

En el marco de dicha reunión, cuyo orden del día estaba insoslayablemente signado por los sucesos del Atlántico Sur, la delegación panameña se convirtió en el paladín de la defensa de la soberanía argentina sobre las Islas Malvinas. Además, a través de una encendida y recordada alocución del Dr. Illueca, justificó la "Operación Rosario”, en tanto hecho descolonizador. Más aún, el canciller panameño aseveró que Argentina estaba ejerciendo sus legítimos derechos de reivindicación soberana, haciéndole "un gran servicio a la América Latina" (CSNU, Sesión 2350, 1982, p. 10).

No obstante, la defensa a la postura argentina no se limitó a una cuestión retórica, sino que además la delegación panameña redactó un proyecto de resolución (S/14950), en el que, recordando las resoluciones de la Asamblea General tendientes a la descolonización de los pueblos (1514/XV y en particular 2065/XX), y teniendo presente diversas declaraciones del Movimiento de NOAL, el Consejo exhortaría a que el Reino Unido-y no la Argentina- se abstuviese de toda amenaza o uso de la fuerza, en aras de colaborar con la República Argentina para la pronta descolonización de las Islas Malvinas.

\footnotetext{
${ }^{13}$ Un día antes, la Cancillería panameña ya había hecho circular una declaración oficial firmada por el Dr. Illueca apoyando la legítima causa argentina.
} 
Como era de esperarse, el proyecto panameño fue rechazado in límine por el Reino Unido. La delegación panameña decidió, considerando la inviabilidad del mismo, abstenerse de someterlo a votación, con el objeto de "presentar ese mismo proyecto, posiblemente fortalecido con otros elementos, cuando este problema, que no es resuelto hoy por el Consejo, tenga que volver aquí” (CSNU, Sesión 2350, 1982, p. 23) ${ }^{14}$. En su lugar se aprobó la resolución 502, fruto de un proyecto presentado por el delegado británico ${ }^{15}$. Este proyecto fue aprobado con 10 votos a favor, 4 abstenciones - provenientes del bloque comunista y España-. Panamá fue el único miembro del Consejo en votar en contra. Ni la Unión Soviética ni la República Popular China hicieron uso de su legítimo derecho de veto. En este contexto, Illueca aseveró que dicha resolución contenía "los elementos para la agravación del conflicto y no para su solución” (CSNU, Sesión 2350, 1982, p. 23), al exigir la cesación de hostilidades inexistentes y la retirada inmediata de las fuerzas argentinas de su propio territorio.

Ha de señalarse, por otra parte, que el proyecto de resolución panameño definía a los acontecimientos del Atlántico Sur como una "situación de tensión" entre ambos países. Bien por el contrario, la resolución finalmente adoptada (502), declaraba la existencia un "quebrantamiento de la paz en la región de las Islas Malvinas"16.

Finalmente, siendo el último orador de la sesión, el delegado panameño cerró su alocución advirtiendo, a suerte de premonición, que:

la resolución 502 (1982) en modo alguno autoriza al Reino Unido a usar la fuerza a través de sus unidades navales o su marina de guerra. Que quede claro que el Consejo no ha autorizado al Reino Unido para una operación bélica como la que está actualmente desarrollando a través del Atlántico y que se dirige ahora hacia el territorio argentino de las Islas Malvinas (CSNU, Sesión 2350, 1982, p. 24).

\footnotetext{
${ }^{14}$ La estrategia panameña consistía en plantear nuevamente su postura una vez que el Reino Unido efectivamente irrumpiera con sus tropas en el archipiélago, toda vez que éstas ya estaban camino a las Islas.

15 Illueca llegó a rechazar, incluso, la utilización del nombre "Falkland" ( sic), en tanto éste constituía una "ofensa histórica" para la Argentina. Por otra parte, sostuvo que, a entender de Panamá, los sucesos del 2 de abril de 1982 no suscitaron quebrantamiento de la paz alguno, sino que dicho quebrantamiento se produciría en vista del envío, por parte del Reino Unido, de "una flota de guerra con el propósito de atacar a la Argentina" (CSNU, Sesión 2350, 1982, p. 11).

${ }^{16}$ Lejos de tratarse de una cuestión semántica, la diferencia es de suma importancia, puesto que el Consejo de Seguridad está facultado para la determinación de la existencia de una amenaza a la paz, quebrantamiento de la paz o acto de agresión. Son éstas las tres causales para la activación de un mecanismo de seguridad colectiva por parte del Consejo. Efectuada tal determinación, el CS puede resolver la aplicación de medidas provisionales tales como el retiro de tropas. En efecto, la resolución 502 exigió la "retirada de todas las fuerzas argentinas de las Islas Malvinas” (cfr. Mársico, 2015, p. 829).
} 
Allende los avatares y las vicisitudes del conflicto que estaba eclosionando, ha de destacarse que el comportamiento de la diplomacia panameña en aquella sesión del Consejo expresó la vocación autonomista del país centroamericano, al entrar en abierta contradicción con los repartidores supremos del régimen político internacional en pos de los principios de su política exterior. Panamá hizo gala del ideario de su doctrina no alineada ${ }^{17}$, dinámica y nacionalista por medio del apoyo solitario, aunque sustantivo, de una causa que, sin dudas, trascendía los australes confines argentinos, abrevando en la idea de Patria Internacional expresada por el ya finado Omar Torrijos.

Luego de la adopción de la resolución 502, el Consejo volvió a colocar al asunto de las Malvinas en su orden del día recién en la sesión $2360^{\text {a }}$, del 21 de mayo ${ }^{18}$. Para ese entonces, ya era evidente que las advertencias del canciller panameño, efectuadas en la sesión del 3 de abril, eran absolutamente atinadas, puesto que el verdadero quebrantamiento de la paz se produjo ante el desembarco de las tropas británicas, eclosionando el conflicto en plenitud. Más aún, el propio vicecanciller argentino Enrique Ros, admitió que las afirmaciones de Illueca pronunciadas un mes y medio atrás en el mismo recinto eran premonitorias ( $c f r$. CSNU, Sesión 2360, 1982, p. 4).

En su alocución del 22 de mayo ante el Consejo, Illueca reiteró su condena contra la expedición punitiva emprendida por el Reino Unido, reiterando su apoyo a los buenos oficios del Secretario General Pérez de Cuéllar. Asimismo, nuevamente relacionó la gesta descolonizadora argentina con las ideas del latinoamericanismo y el tercermundismo, al tiempo que denunció que la resolución 502 -allende la oposición panameña a la misma- había sido flagrantemente incumplida por el Reino Unido, puesto que ésta no habilitaba a la Albión a la belicosidad. Como novedad, el delegado panameño esgrimió una crítica al Tratado Interamericano de Asistencia Recíproca (TIAR), expresando que

el TIAR ha resultado ineficaz y América Latina carece ahora de un sistema de seguridad [...] [La connivencia de los miembros de la OTAN, en detrimento del TIAR] es preocupante y causa un tremendo resentimiento contra los británicos y contra todas las naciones que están prestándose para que el Reino Unido siga cometiendo esta agresión contra la Argentina. Eso no puede pasar sin registrarse. Por eso consideramos que

\footnotetext{
${ }^{17}$ Prueba del componente no alineado de la postura panameña es, sin dudas, la mención, por parte de Illueca de los casos de Goa, en India y Suez, en Egipto, en tanto reacciones tercermundistas-con la venia de la ONUante el colonialismo.

${ }^{18}$ Es dable destacar que esta sesión $\left(2360^{a}\right)$ se llevó a cabo en virtud de una carta de la delegación panameña que así lo solicitaba. Existió también una nota del delegado de Irlanda en aras de un encuentro del CS, pero esta estaba fechada el 4 de mayo.
} 
la raíz del problema es colonial, que el Reino Unido está en contra de lo que es el orden jurídico de las Naciones Unidas (CSNU, Sesión 2362, 1982, p. 17).

Al día siguiente, haciendo nuevamente uso de la palabra ante el Consejo, Illueca se manifestó en contra las afirmaciones de la Primera Ministra británica, que tendían a la avidez de la guerra a ultranza y que se oponían a los ofrecimientos de los buenos oficios por parte de las Naciones Unidas (cfr. CSNU, Sesión 2363, 1982, p. 1621). En la sesión del 25 de mayo, Panamá fue, una vez más, el inexorable portador de la postura latinoamericana frente a la Guerra de las Malvinas, presentando una declaración conjunta junto con los cancilleres argentino, nicaragüense y venezolano (cfr. CSNU, Sesión 2366, 1982, p. 10).

En la sesión del 26 de mayo, en la que el Consejo aprobaría por unanimidad la resolución 505, Illueca representó por última vez a Panamá durante la Guerra de Malvinas. En aquella jornada, Panamá respaldó el proyecto de resolución que exhortaba al Secretario General a que prestase sus buenos oficios para arribar a un alto al fuego; observando, no obstante, que el mismo no reunía "todos los elementos para lograr una paz justa y duradera”, al no mencionar la cuestión atinente a la descolonización del archipiélago (CSNU, Sesión 2368, 1982, p. 6).

Finalmente, en las sesiones del 2, 3 y 4 de junio, las últimas en las que el Consejo abordaría la Cuestión Malvinas, Panamá estuvo representado por el diplomático Leonardo Kam -a la sazón Encargado de Negocios ad interim de la Misión Permanente de Panamá ante las Naciones Unidas-. Aquellos encuentros fueron solicitados, justamente por la delegación panameña, que junto con su contraparte española elaboró un nuevo proyecto de resolución (S/15156/Rev.1) en aras de un cese al fuego inmediato en el Atlántico Sur, ante los escasos progresos de la resolución 505. Empero, el proyecto hispano-panameño fue, en primer término, demorado; para finalmente sucumbir ante el doble veto británico y estadounidense (CSNU, Sesión 2373, 1982).

Como hemos visto, la posición panameña en el Consejo de Seguridad ante la Guerra de Malvinas ha sido profundamente consecuente con los principios de su política exterior. Más allá de la clara postura pro argentina, a los efectos del presente artículo, caben destacarse las justificaciones de la misma. En efecto, la retórica panameña, como así también su praxis negociadora y la pluma de sus proyectos de resolución, estuvo atravesada y enraizada en el concepto clave de descolonización, en plena concomitancia con las ideas puigianas de la vocación autonomista. No caben dudas de que ha sido la diplomacia panameña quien, por antonomasia, llevó la voz cantante del no alineamiento y del tercermundismo durante la crisis de las Malvinas. 
No menos estoica ha sido la defensa de Panamá a la República Argentina en el seno de la Organización de los Estados Americanos, aunque la respuesta de tal organismo estuvo influenciada y supeditada al hecho de que el Consejo de Seguridad de la ONU estuviese tratando el asunto (Connell-Smith, 1982, p. 343). Ello no impidió que, como es de suponerse, en este foro la postura argentina sea galvanizada y apoyada por la inmensa mayoría de los Estados miembro, de suerte que la voz panameña no hubo de destacarse como en sus altivas intervenciones en el CS de la ONU. De todos modos, los aportes allí vertidos por Panamá estuvieron en armonía con los principios de su política exterior, al situar el contencioso en una lógica descolonizadora, en el marco del conflicto Norte-Sur (Krepp, 2017, p. 355). Por otra parte, se explicitó, en el seno de la OEA una feroz crítica a los Estados Unidos por su connivencia y apoyo a los objetivos británicos, en detrimento del Tratado Interamericano de Asistencia Recíproca. A tal respecto, el delegado panameño denunció el trato "burlón” de Washington hacia América Latina (Krepp, 2017, p. 35).

Ha de mencionarse, por otra parte, que las relaciones bilaterales entre Panamá y los Estados Unidos también se vieron convulsionadas por el conflicto angloargentino. En efecto, el presidente panameño Arístides Royo envió una carta a su par norteamericano Ronald Reagan por medio de la cual le solicitaba que las bases militares de la Zona del Canal no fuesen utilizadas para apoyar directa o indirectamente al Reino Unido, en función del Tratado de Neutralidad del Canal suscripto en $1977^{19}$. En dicha comunicación, el Jefe de Estado centroamericano razonaba, incluso, sobre la ruptura simbólica entre la América Anglosajona y la Latina, al denunciar la violación de facto de la Doctrina Monroe. Desde la óptica de la autonomía, esta postura panameña implica, una vez más, el deslinde entre el interés nacional de la potencia dominante y el interés estratégico del bloque -al discrepar abiertamente con el hegemón en una cuestión de orden primero, aunque sin menoscabo del reconocimiento de su liderazgo hemisférico y del bloque ( $c f r$. Puig, 1984, p. 78).

Extraordinario y consecuente corolario del comportamiento de la diplomacia panameña durante la Guerra de las Malvinas es sin dudas el discurso del Presidente Royo ante el Segundo período de sesiones de la Asamblea General de la ONU destinado al desarme- irónicamente pronunciado el mismo día del cese de

\footnotetext{
${ }^{19}$ Desde 1979, los nuevos Tratados del Canal se encontraban en implementación paulatina; los Estados Unidos conservaban para su usufructo la mayor parte de las bases militares de la Zona hacia 1982. En su misiva destinada a Ronald Reagan, el presidente Royo solicitaba "la formal promesa del Gobierno estadounidense de que ninguna de esas instalaciones y personal, o las áreas que utilizan, se verán relacionadas con acciones que, directa o indirectamente, contribuyan a perjudicar intereses argentinos o de cualquier otro pueblo latinoamericano, o propendan a favorecer las acciones británicas que los panameños desaprobamos" (El País, $1^{\circ}$ de junio de 1982).
} 
hostilidades en el Atlántico Sur. En sus palabras, el mandatario recorrió sucintamente la postura panameña al respecto, con un pathos reminiscente de la retórica torrijista, al poner en evidencia la imperiosa necesidad descolonizadora, junto con una definición esclarecedora de lo que el tercermundismo implicaba en las postrimerías del siglo XX.

Durante la Guerra de las Malvinas, Panamá hizo gala de su prestigio internacional y de las ideas torrijistas de la "Patria Internacional", enraizadas en una matriz de pensamiento profundamente autonomista. Como habría de aseverar el entonces canciller argentino Nicanor Costa Méndez en sus memorias, redactadas años después:

Panamá había experimentado a lo largo de casi toda su historia las consecuencias negativas de la acción de las grandes potencias en el Caribe. Tanto el pueblo panameño como su gobierno conocían las dificultades, las luchas y los retrasos que toda política exterior independiente demanda y trae consigo. El propio embajador Illueca había sido uno de los representantes de Panamá en la muy reciente negociación que ese país había mantenido con los Estados Unidos para modificar la situación política del istmo y del Canal. Nadie mejor que él, entonces, para comprender nuestro caso, para acompañar a la Argentina y para ser en el Consejo de Seguridad su vocero y su fraternal aliado [...] Su hidalguía no fue irracional ni su actitud puramente emotiva. Sostuvo su posición con claros e incontestables argumentos jurídicos, con un sentido de la justicia y a la vez con un realismo político que ninguno de sus pares supo exhibir.

Su visión fue clara y los hechos le dieron luego la razón.

La actitud de Panamá y los discursos de los representantes de los países hermanos de Latinoamérica señalaron el comienzo de un movimiento de solidaridad que constituye uno de los hechos más destacados y destacables de toda la gesta. (Costa Méndez, 1993, p. 202-203) ${ }^{20}$.

\section{4- Consideraciones finales}

Hemos revisitado la postura de la República de Panamá en torno a la Cuestión Malvinas durante el período torrijista. Si bien el apoyo panameño se mantuvo incólume en toda la etapa estudiada, es innegable que el mismo arribó a su cénit en 1982, en el marco de la participación del país en las sesiones del Consejo de Seguridad de las Naciones Unidas durante la Guerra del Atlántico Sur.

\footnotetext{
${ }^{20}$ Las cursivas son nuestras. Es preciso destacar que Jorge Illueca sería condecorado en Buenos Aires con la Orden del Libertador San Martín, en el marco de su visita oficial a la Argentina en calidad de vicepresidente de Panamá en enero de 1983.
} 
Más allá del sostenido apoyo del país centroamericano a la República Argentina en esta cuestión trascendental para nuestra política exterior, vale destacar las justificaciones esgrimidas por Panamá para el sostenimiento de su posición: éstas estaban enraizadas en una retórica y pathos anticolonialistas, en concomitancia con la gesta que, en el mismo período, era librada en pos de la reafirmación de la soberanía sobre el Canal de Panamá y su Zona.

Por otra parte, y tal como hubo de ser pregonado en el caso de la disputa por el Canal de Panamá, la estrategia negociadora tendiente a la internacionalización y multilateralización del conflicto bien pueden ofrecerse como posibles vías a adoptar por parte de la República Argentina en aras de obligar al Reino Unido a discutir la cuestión de la soberanía sobre las Islas Malvinas.

Finalmente, y como el propio Puig (1983, p. 37) reconocería, en los casos en los que el reclamo soberano no se trata de un simple caso de descolonización, sino que el mismo implica un cuestionamiento sustancial del régimen internacionalsiendo la Cuestión Malvinas un óptimo ejemplo, "el accionar del gobierno panameño con respecto al Tratado del Canal constituye un buen ejemplo de estrategia por seguir, en casos de obstinada renuencia de la potencia responsable de una situación injusta”. En tal sentido, colegimos que es menester estudiar cuidadosamente las estrategias negociadoras llevadas adelante por Panamá para lograr el ejercicio de su soberanía sobre la totalidad de su territorio. Éstas bien podrían, mutatis mutandis, arrojar luz en pos de la descolonización de nuestros territorios ocupados ilegítimamente por el Reino Unido.

\section{Referencias bibliográficas}

Archivo DiFilm [archivodichiara] (19 de febrero de 2017). Omar Torrijos Herrera sobre las Islas Malvinas Argentinas - DiFilm (1977) [archivo de video]. Recuperado de: https://www.youtube.com/watch?v=cZW 1W 4tpdu0

Cardozo, J. (compilador) (2013). Primer Congreso Latinoamericano. Malvinas, una causa de la Patria Grande, Ediciones de la Universidad Nacional de Lanús, Lanús. [1 $1^{\mathrm{a}}$ edición: 2011].

Ceberio, J. (23 de abril de 1983). Los panameños votan hoy una reforma constitucional que pone fin de hecho a la 'era Torrijos', a los dos años de su muerte, El País, Madrid. Recuperado de: https://elpais.com/diario/1983/04/24/internacional/419983204_850215.html Connell-Smith, G. (1982). The OAS and the Falklands (sic) Conflict, en The World Today, Vol. 38, No. 9.

Costa Méndez, N. (1993). Malvinas. Ésta es la historia, Editorial Sudamericana, Buenos Aires. 
CSNU. 2350a sesión, Nueva York, 3 de abril de 1982. Disponible en: https://undocs.org/es/S/PV.2350(OR)

CSNU. 2360a sesión, Nueva York, 21 de mayo de 1982. Disponible en: https://undocs.org/es/S/PV.2360(OR)

CSNU. 2362 ${ }^{\text {a }}$ sesión, Nueva York, 22 de mayo de 1982. Disponible en: https://undocs.org/es/S/PV.2362(OR)

CSNU. 2363a sesión, Nueva York, 23 de mayo de 1982. Disponible en: https://undocs.org/es/S/PV.2363(OR)

CSNU. 2366 sesión, Nueva York, 25 de mayo de 1982. Disponible en: https://undocs.org/es/S/PV.2366(OR)

CSNU. 2368 a sesión, Nueva York, 26 de mayo de 1982. Disponible en: https://undocs.org/es/S/PV.2368(OR)

CSNU. 2373a sesión, Nueva York, 4 de junio de 1982. Disponible en: https://undocs.org/es/S/PV.2373(OR)

Declaración conjunta Argentino-Panameña (1974). Recuperado de: https://tratados.cancilleria.gob.ar/tratado_archivo.php?tratados_id=kqGql5s= $\&$ tipo $=\mathrm{kg}==\& \mathrm{id}=\mathrm{k} 6 \mathrm{GnmA}==\&$ caso $=\mathrm{pdf}$

El País (1 de junio de 1982). El presidente panameño razona la ruptura entre las dos Américas, Madrid. Disponible en: https://elpais.com/diario/1982/06/02/internacional/391816809_850215.html

Greene, G. (1985). El General, Fondo de Cultura Económica, México. [1ª edición en inglés: 1984].

Jaén Suárez, O. (2007). "Historia de las Negociaciones de los Tratados TorrijosCarter" en Revista Cultural Lotería. N ${ }^{\circ}$.473-474.

Krepp, S. (2017). A view from the South: The Falklands/Malvinas and Latin America, en Journal of Transatlantic Studies, 15:4.

Mársico, O. (2015). "El uso de la fuerza en las Relaciones Internacionales" en González Napolitano, S. (Coord.), Lecciones de Derecho Internacional Público, Erreius. Buenos Aires.

Ministerio de Relaciones Exteriores de la República de Panamá. (1976). Memoria presentada a la Honorable Asamblea de Representantes de Corregimientos por S.E. Aquilino E. Boyd Ministro de Relaciones Exteriores.

Morasso, C. (2015). La cooperación Sur-Sur argentina con África Subsahariana en materia agrícola (2003-2012), tesis de Doctorado en Relaciones Internacionales, Universidad Nacional de Rosario (UNR), Rosario.

Puig, J. C. (1971). "La vocación autonomista en América Latina: heterodoxia y secesionismo" en Revista de Derecho Internacional y Ciencias Diplomáticas, 39/40, Rosario. 
Puig, J. C. (1983). Malvinas y régimen internacional, Depalma, Buenos Aires.

Puig, J.C. (1984). "Introducción”, en América Latina: politicas exteriores comparadas, Grupo Editor Latinoamericano, Buenos Aires.

Ropp, S. (1992). "Explaining the Long-Term Maintenance of a Military Regime: Panama before the U.S. Invasion” en Word Politics, 44.

Tack, J.A. (1981). "La lucha de Omar Torrijos por la recuperación de la Integridad Territorial” en Revista Cultural Lotería. N ${ }^{\circ}$.305-9 Vol. 1.

Vargas, D. (2004). Omar Torrijos Herrera y la Patria Internacional, Fundación Omar Torrijos, Panamá.

Vargas, D. y Zárate, M. (Eds.) (2017). General Omar Torrijos, de Panamá y de la Patria Grande, 2a edición, Manuel Orestes Nieto, Panamá. [1ª edición: 2010]. 